\title{
Evaluation Frequency of Merkel Cell Polyoma, Epstein-Barr and Mouse Mammary Tumor Viruses in Patients with Breast Cancer in Kerman, Southeast of Iran
}

\author{
Malekpour Afshar Reza', Mollaie Hamid Reza ${ }^{2 *}$, Lashkarizadeh Mahdiyeh ${ }^{3}$, \\ Fazlalipour Mehdi' ${ }^{4}$, Zeinali Nejad Hamid ${ }^{5}$
}

\begin{abstract}
Breast cancer is the most common cancer among women worldwide. Roles of the Epstein-Barr, Merkel cell polyoma and mouse mammary tumor viruses in breast carcinogenesis are still controversial although any relationship would clearly be important for breast cancer etiology, early detection and prevention. In the present study associations between EBV, MMTV and Merkel cell polyoma virus and breast cancer in 100 Iranian patients were evaluated using paraffin-embedded tissues. EBER RNA and expression of p53 and large T antigen were evaluated by real time PCR and CD34, p63, HER2, PR and ER markers were studied by immunohistochemistry. EBV was detected in 8/100 (8\%), MMTV in 12/100 (12\%), MPy in 3/100 (3\%) and EBER RNA in 18/100 (18\%) cases. None of the control samples demonstrated any of the viruses.p53 was suppressed in EBV, MPy and MMTV positive samples. The large $T$ antigen rate was raised in MPy positive samples. Our results showed that EBV, MMTV and the Merkel cell polyoma virus are foundwith some proportion of breast cancers in our patients, suggesting that these viruses might have a significant role in breast cancer in Kerman, southeast of Iran .
\end{abstract}

Keywords: Breast cancer - Epstein-Barr virus - Merkel cell polyoma virus - mouse mammary tumor virus

Asian Pac J Cancer Prev, 16 (16), 7351-7357

\section{Introduction}

Breast cancer is the leading type of cancer in women in Worldwide which develops in breast tissue, including lump, dimpling of the skin, a change in breast shape, fluid coming from the nipple, or a red scaly patch of skin. This cancer is more common in developed countries which is raising in the middle income countries and is 100 times more common in women than in men(Ito and Matsuo, 2015). Family history is risk factors for breast cancer and about $5-10 \%$ of cases are due to inherited genes including BRCA1 and BRCA2 (Tao et al., 2014). The breast cancer diagnosis is confirmed by taking a biopsy of the concerning lump. Risk factors for developing breast cancer are sex, obesity, lack of physical exercise, drinking alcohol, radiation, having children late or not at all, and older age. Other external factors also play roles for progression of cancer (Rahman et al., 2015).

The International Agency for Research on Cancer (IARC) reports that biological carcinogens cause 18-20\% of cancers. Viruses have been reported as a cause in the development of cancers which have been considered for breast cancer. Polyoma virus, Epstein-Barr virus and Mouse mammary tumor virus (MMTV) are viral agents which have been linked to breast cancer (Ban and Godellas, 2014).

Mouse mammary tumor virus (MMTV) is a major cause of mammary tumors in mice. This virus is B-type retrovirus and exists both as endogenous proviruses transmitted vertically and exogenous infectious viruses transmitted horizontally.

In mice, the HMTV (Human mammary tumor virus) leads tumor formation through the insertion mutagenesis of Wnt oncogenes, thereby promoting its activation. It has been indicated that HMTV is associated preferentially with breast cancer and is not present in normal breast tissue (Franci et al., 2013; Tabriz et al., 2013).

Epstein-Barr virus (EBV) in Herpesvirals family has been implicated as a cause of breast cancer, which is classified as a class I carcinogen by IARC. EBV is associated with several malignancies, including Burkett's and Hodgkin's lymphoma, nasopharyngeal carcinoma

${ }^{1}$ Kerman University of Medical sciences, Afzalipour School of Medicine, Research Center of Infectious and Tropical Diseases, ${ }^{2}$ Medical Virology, Gastrointestinal and Liver Research center, Department of Medical Virology, Kerman University of Medical Sciences, Kerman, ${ }^{3}$ Pathology and stem cell research center, Kerman University of Medical sciences, ${ }^{4}$ Medical Virology, Department of Arboviruses, Institute of pasture, Tehran, ${ }^{4}$ Kerman University of Medical sciences,Afzalipour School of Medicine, Department of Phisiology, Kerman, IRAN Iran *For correspondence: hamid2008kmu@gmail.com 
(NPC), and BC (Breast Cancer) (Joshi et al., 2009; Hippocrate et al., 2011).

The presence of EBV DNA was linked to severe forms of breast cancer. Epstein-Barr virus encoded small RNA (EBER) is nonpolyadenylated, noncoding RNA that exists abundantly in EBV-infected cells. EBER induces signaling from the Toll-like receptor 3 (TLR3), which is a sensor of viral double-stranded RNA (dsRNA) and induces type I IFN and proinflammatory cytokines and the majority of the released EBER existed as a complex with a cellular EBER-binding protein (Deshpande et al., 2002; Arbach et al., 2006). Merkel cell polyomaviruses (MCV) isolated from skin cancer called Merkel cell carcinoma (MCC) is not only integrated into the host cell DNA, but also has mutations in the viral oncogene large T (LT) antigen, shorten the MCV LT helicase and thereby preventing auto reactivation of integrated virus replication that would be important for cell survival. The oncogenic potential of MCPyV may interact to its $\mathrm{T}$ antigen with the cellular retinoblastoma tumor suppressor protein (pRb) (Antonsson et al., 2012; Corbex et al., 2014). The most frequently mutated genes in breast carcinomas are the p53 tumor suppressor gene. When the p53 gene is mutated, the cell cycle controlling is lost and this fact is leading to the development of neoplasm. The present study was carried out in an attempt to determine whether there is a relationship between mentioned viral infection and p53 expression in breast carcinomas (Vernet-Tomas et al., 2015). Molecular techniques are the most reliable assays in viral presence detection in comparison to other tests based on host antibody.Real-Time PCR is the most sensitive methods and have been used frequently to detect viruses(Ito and Matsuo, 2015). In this study, the presence of EBV, MMTV and Merkel cell polyomavirus in BC tissue samples were studied from paraffin-embedded malignant tissues in Iranian patients with breast cancer by a standard Real Time PCR assay for finding the relationship between those viruses and breast cancer.

\section{Materials and Methods}

\section{Patients}

Paraffin embedded block samples from patients with Breast Cancer, Academic and private Pathobiology Lab, Kerman province, Iran, during April 2006 -March 2014 were identified. A total of 109 specimens found, but 100 formalin-fixed, paraffin-embedded tumor tissues of patients collected and other patients were lost due to inadequate, absence of histological material. The present study is based on a retrospective examination of the Breast Cancer diagnostic biopsy or surgery samples from clinical cases, all original hematoxylin and eosin (H\&E) slides and Immunohistological stain recut from tissue blocks were reviewed. In total, samples were screened EBV DNA, MMTV DNA, MPy DNA, mRNA expression level of EBER, the expression level of large $T$ antigen and level of expressing p53. This project was approved by the tropical infectious research center ethics committee of the Kerman University of Medical Sciences.
We performed Immunohistochemistry analyses on 100 cases of invasive ductal carcinoma. Patients included in this study were from hospitals in the city of Kerman (Afzalipour, Shahid Bahonar) and private laboratories. Formalin-fixed, paraffin blocks of tumor and non-tumor tissue sections from each patient were re-examined by pathologists and classified according to the Nottingham combined system histological grading scheme which included mitotic rate, nuclear and structural properties. Specimens were classified as grades 1,2, and 3. The block from each tumor sample with areas of invasive cancer, DCIS, atypical ductal hyperplasia and flat epithelial atypia, (DIN Ia, Ib), fibrocystic changes and normal areas were selected for further analyses. If these were not located on one block, the specific areas of the different blocks were cut and placed on one slide. Serial sections of $5 \mu \mathrm{m}$ were obtained from each block and mounted on silanized slides for immunohistochemical staining. Dehydrated, deparaffinized sections along with retrieval buffer were microwaved for $20 \mathrm{~min}$ ( $3 \mathrm{~min}$ at 850 watts; $17 \mathrm{~min}$ at 180 watts), then blocked for 10 min with $0 / 5 \% \mathrm{H} 2 \mathrm{O} 2$. Sections were incubated for 1 hour at room temperature with the monoclonal antibodies as follows: ER (1:50; DAKO, Clone 1D5); PR (1:100; DAKO, Clone PgR 636); HER2-neu (1:100; DAKO), CD34 (1:100; DAKO, Clone QBEnd 10); CD34 (1:100; Novocastra, Clone QBEnd 10); and SMA (DAKO, Clone 1A4): Ready to use. Slides were rinsed with wash buffer for $5 \mathrm{~min}$, which was repeated twice, between all main stages. Envision polymer (30 min) was added using 3, 3'-diaminobenzidine (DAB) as the chromogen (10 min) followed by staining with hematoxylin for 2 min, dehydration and mounting the slides.

\section{Deparaffination samples}

Paraffinated blocks from the 100 tumor samples and normal tissues were cut in 5- $\mu \mathrm{m}$ sections and 8 sections, patients were collected in the same micro-centrifuge tube. Samples were de-waxed in $500 \mu$ xylene; All microcentrifuge tube located about $10 \mathrm{~min}$ in a $60^{\circ} \mathrm{C}$ heated block and centrifuged at 8,000 RPM, the supernatant was removed. This step was then repeated 3 times. Add $500 \mu \mathrm{l}$ absolute ethanol, centrifuge at 10,000 RPM for $1 \mathrm{~min}$, the samples were then dried in a $60^{\circ} \mathrm{C}$ heated block with open lids for 10-20 min for remove residual ethanol.

\section{Tissue digestion}

According to samples (biopsy or Paraffinated blocks), 200-400 $\mu$ l of Tissue Lysis Buffer was added to each tube [4 M Urea, 200 metros, $20 \mathrm{mMNaCl}, 200 \mathrm{~mm}$ EDTA; $\left.\mathrm{PH}=7.4\left(25^{\circ} \mathrm{C}\right)\right]$. To all tubes added $20-40 \mu$ proteinase $\mathrm{K}$, Samples were gently vortexes and located about $10 \mathrm{~min}$ in a $60^{\circ} \mathrm{C}$ heater block, and all samples were subsequently incubated at $37^{\circ} \mathrm{C}$ overnight.

\section{DNA and RNA extraction}

The next day, $200 \mu \mathrm{l}$ of Binding Buffer [6 M Guanidine- $\mathrm{Hcl}, 10 \mathrm{mM}$ Urea, $10 \mathrm{mM}$ Tris-Hcl, $20 \%$ Tritonx-100 (v/v); $\left.\mathrm{PH}=4.4\left(25^{\circ} \mathrm{C}\right)\right]$ was added to each tube with gently vortex. DNA was isolated using a QIAamp DNA Mini kit (Qiagen, Germany) and Total RNA were 
extracted using the RNAeasy mini kit (Qiagen, Germany) according to the manufacturer's instructions. Extracted DNA and RNA pellets were resuspended in $100 \mu \mathrm{l}$ of pre-warmed Elution buffer and stored at $-70^{\circ} \mathrm{C}$ until use.

Virus detection uses real time PCR

Real time PCR was carried out using EBV, MPy and MMTV Real Time PCR kit (Inter Lab Service, Russia) following instruction manual.

\section{rReal Time PCR}

For the determination, the expression level of EBER, p53 and large T- antigen mRNA, reverse transcription real time PCR (rReal Time PCR ) was carried out by using the first strand cDNA synthesis kit by Revert AidcDNA synthesis kit (Thermoscientific, USA). Briefly, RNA samples were heated to $65^{\circ} \mathrm{C}$ for 10 minutes and then chilled on ice. The uniform suspension of bulk firststrand cDNA reaction mix was added according to the manufacturer's protocol.

One $\mu$ l of DTT solution, and $1 \mu$ of random Hexamer (N) 6 primer $(0.2 \mu \mathrm{g})$ were then added to the heat-denatured RNA. Samples were mixed properly by pipetting up and down several times and then incubated for 1 hour at $42^{\circ} \mathrm{C}$. For Real time PCR, the QuantiTect Probe PCR Kit (Qiagen, Germany) used base on instruction kit. Real time PCR primers and probes were designed for EBER, p53 and T antigen mRNA after alignment of these regions between all of them in EBML-EBI and as an internal control, $\beta$-Actin were purchased from Metabion company (Germany) (Table1) .

\section{Statistical analysis}

Chi-square test or Fisher's exact test was conducted using SPSS version 17 for the association between the presence of DNA virus genome and other characterizes (values $\mathrm{P}=0.05$ were considered statistically significant).

\section{Results}

In our study, 100 female with breast cancer (Invasive, DCIS, DIN) and 100 breasts normal tissues (mean age $49.03 \pm 11.58)$ were used. We included 100 females diagnosed with the invasive ductal carcinoma of the breast; with a mean age of $49.1 \pm 1.1$ years and mean tumor size of $3.2 \pm 0.2 \mathrm{~cm}$. The mean number of the involved axillary lymph nodes was $8.1 \pm 0.8$ and the following tumor grades were reported: grade I (35\%), grade II (42\%), and grade III (23\%) (Table2). The Real-time PCR results were shown in Table 3 and as it is clear, 8 cases $(8 \%)$ were EBV DNA positive in breast cancer samples and 10 cases (22.2\%) was positive in lymph nodes and the EBER RNA expression rate was positive in $18(\%)$ cases in breast cancer samples and $25(55.5 \%)$ cases in lymph nodes. For MMTV DNA, $12(12 \%)$ was positive in breast cancer samples and 14 (71.4\%) was positive in lymph nodes. Positive Real-time PCR result in MPy DNA was $3(3 \%)$ in breast cancer samples and $8(17.7 \%)$ in lymph nodes. The expression of p53 was shown in Figure 1 and as it is clear, the rate of p53 was down regulated in EBV, MPy and MMTV positive samples comparing to negative samples .

Large $\mathrm{T}$ antigen expression level was evaluated in Figure 2 and sharp raised level was detected in MPy positive samples (0.8), although slight rate of LTag was detected in other samples. In Figure 3 , the expression rate of EBER RNA was shown and based on our expectation it was high in EBV positive samples and very slight low level was detected in MPy and EBV negative samples. No expression was shown in negative MPy and MMTV positive and negative samples. Based on Figure 4, different Immunochemistry markers were evaluated in invasive tumors and the rate of CD34 was shown on top that shows the increased level and after that the rate of

\section{P53}

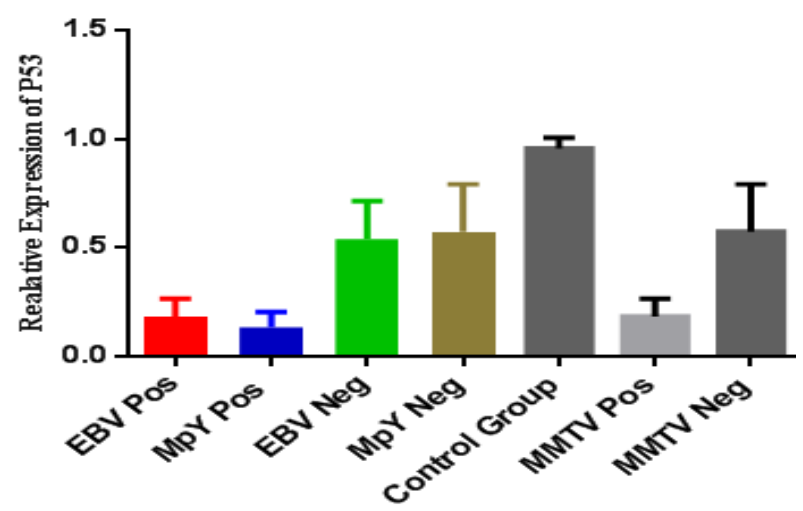

Figure 1. Relative Expression of p53 in Different Samples

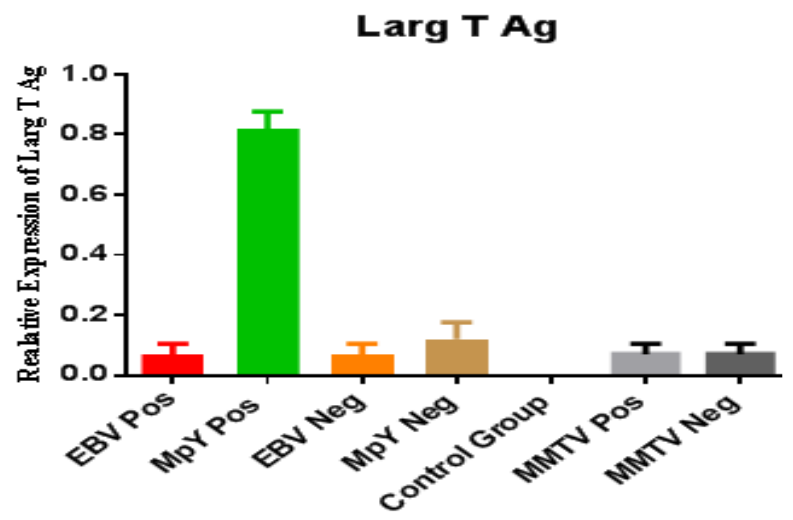

Figure 2. Relative Expression of LTag in Different Samples

Table 1. Sequence Primer and Probes for Real Time PCR in this Study

\begin{tabular}{|c|c|c|c|c|}
\hline Name & Forward & Reverse & Probe & Location \\
\hline P53 & АTCTTATCCG & ATGGTGGTACAG & CCAACCTCAGGCGC & $147-269$ \\
\hline Large $\mathrm{T}$ & \multirow{2}{*}{ GCAGCCTATGTATGGTATG } & \multirow{2}{*}{ CCTGGAAGTTCCTCTGTC } & \multirow{2}{*}{$\begin{array}{c}\text { ACTCTAACCTCCTCTACCT } \\
\text { GAGCA }\end{array}$} & \multirow{2}{*}{$201-272$} \\
\hline antigen & & & & \\
\hline EBER & TGAGGAGATGTAGACTTGTA & CTGGTACTTGACCGAAGA & AACCTCAGGACCTACGCTGC & $138-321$ \\
\hline
\end{tabular}


p63 was detected. Other markers such as ER, PR and HER 2 were detected at low level. In Figure 5 different Immunochemistry markers were evaluated in DCIS Tumors and in first position the highest level of CD34 detected and the p63 was shown in second position. Other markers such as ER, PR and HER2 were detected at low level. Different Immunochemistry markers were evaluated in DIN Tumors in Figure 6 and highest level of

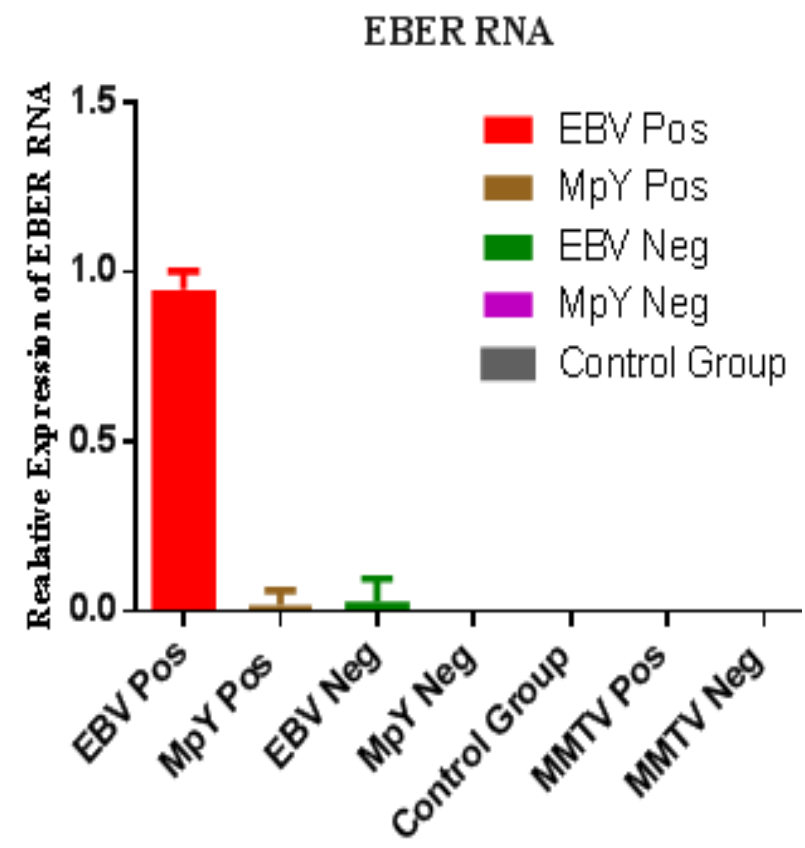

Figure 3. Relative Expression of EBER RNA in Different Samples

Table 2. Patient and Tumor Characteristics

\begin{tabular}{|c|c|c|}
\hline Age group (years) & No $(\%)$ & Mean \pm SD \\
\hline$<50$ & $60(60)$ & \multirow{2}{*}{$49.1 \pm 1.1$} \\
\hline$>50$ & $40(40)$ & \\
\hline Tumor size $(\mathrm{cm})$ & No $(\%)$ & Mean \pm SD \\
\hline$<2$ & $17(17)$ & \multirow{3}{*}{$3.2 \pm 0.2$} \\
\hline 5-Feb & $70(70)$ & \\
\hline$>5$ & $13(13)$ & \\
\hline Lymph nodes & No $(\%)$ & Mean \pm SD \\
\hline$<3$ & $13(28.9)$ & \multirow{2}{*}{$8.1 \pm 0.8$} \\
\hline$>3$ & $32(71.1)$ & \\
\hline Tumor grade & No $(\%)$ & StDev \\
\hline 1 & $35(35)$ & 0.327 \\
\hline 2 & $42(42)$ & 0.344 \\
\hline 3 & $23(23)$ & 0.438 \\
\hline
\end{tabular}

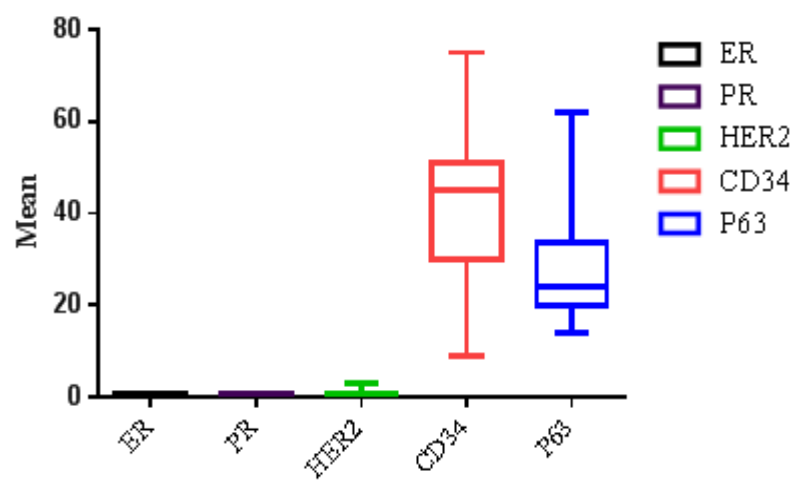

Immunoch emistry Markers

Figure 4. Distribution of Immunochemistry markers in Invasive Tumors

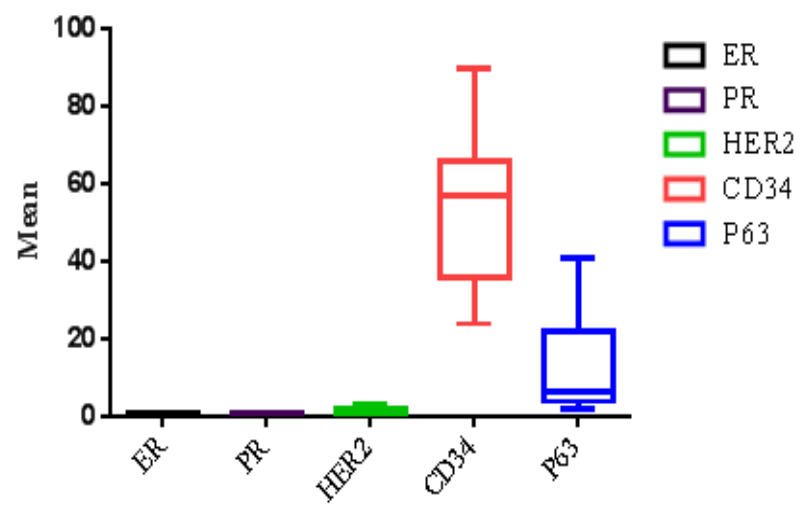

Immunochemistry Markers

Figure 5. Distribution of Immunochemistry markers in DCIS Tumors



Figure 6. Distribution of Immunochemistry markers in DIN Tumors

Table 3. Real timePCR results for EBV, MMTV, MPy and EBER

\begin{tabular}{|c|c|c|c|c|c|c|}
\hline \multirow[t]{2}{*}{ Test } & \multicolumn{2}{|c|}{ Results in Breast cancer } & \multicolumn{2}{|c|}{ Results in Normal tissue } & \multicolumn{2}{|c|}{ Results in Lymph nodes } \\
\hline & Pos $(\%)$ & $\operatorname{Neg}(\%)$ & Pos $(\%)$ & $\operatorname{Neg}(\%)$ & Pos $(\%)$ & $\operatorname{Neg}(\%)$ \\
\hline EBV DNA & $8(8)$ & $92(92)$ & $0(0)$ & $100(100)$ & $10(22.2)$ & $35(77.8)$ \\
\hline MMTV DNA & $12(12)$ & $88(88)$ & $0(0)$ & $100(100)$ & $14(71.4)$ & $31(28.6)$ \\
\hline MPy DNA & 3 (3) & 97(97) & $0(0)$ & $100(100)$ & $8(17.7)$ & $37(82.3)$ \\
\hline EBER RNA & $18(18)$ & $82(82)$ & $0(0)$ & $100(100)$ & $25(55.5)$ & $20(44.5)$ \\
\hline
\end{tabular}


CD34 detected in high position and after that the p63 was shown in second position. Other markers such as ER, PR and HER2 were detected at low level.

\section{Discussion}

Breast cancer is a leading cause of death in women worldwide and has been indicated that the incidence of this malignancy is rising approximately $3 \%$ per year (Forouzanfar et al., 2011). Environmental factors have an important role in the etiology of breast cancer. From the environmental factors, viruses have received considerable attention and also a number of viruses have been implicated in the pathogenesis of breast cancer, including mouse mammary tumour virus (Fernandez et al., 2007; Darbre and Fernandez, 2013) merkel cell polyomavirus and Epstein- Barr virus (Paredes et al., 2005; Mazouni et al., 2011). However, it is not clear that the virus has a central role in the pathogenesis of this malignancy.

The association of EBV, MMTV and Merkel cell polyomavirus with breast cancer comes from data which shows that: (a) they are present in breast tissue, detected in breast milk; (b) their DNA stimulates growth of human breast milk cells; (c) some viral-associated lymphomas occur in the breast. EBV has a high prevalence of breast carcinomas and, in endemic areas, positive samples showed higher loads of the EBV genome (Oskouee et al., 2014; Yahia et al., 2014; Mazouni et al., 2015). The role of different viruses causing human $\mathrm{BC}$ has been investigated with variable results, providing evidence in favor or against it, hence the issue remains controversial. Many researchers have detected the EBV, MMTV and Merkel cell polyomavirus by using real time PCR in human breast cancers (Wang et al., 2014).

But others did not detect the MMTV in 18 human breast cancers they examined Bindra and colleagues found only 1 of 60 human breast cancers by PCR (Bindra et al., 2007). Witt and colleagues tested 50 Austrian human breast cancer samples and did not detect the MMTV env sequence in any of them (Witt et al., 2003). Mant and colleagues detected $16 \%$ of 44 human breast cancer samples, but all were false positives (Mant and Cason, 2004). In 2008, evaluated the presence of MMTV- like virus in invasive breast cancer in 46 Japanese women by PCR and Southern blot hybridization and did not detect any virus particle in the tissue specimen tested (Fukuoka et al., 2008). However, Ford CE et al detected very low ratio of MMTV DNA in Vietnamese and Vietnamese-Australian women $(0.8 \%$ and $0 \%$, respectively) using PCR method (Ford et al., 2004). Molecular method of the virus detection may also change the rate of virus detection in samples. Presence of MMTV-like virus env gene sequence in Italian women by fluorescence nested PCR method which was positive in $33 \%$ of human breast cancer cases(Melana et al., 2002). Formalin used for preparation of formalinfixed paraffin-embedded tissues may fragments the DNA and interfere with PCR amplification of large sequence of DNA templates. A simple way for reducing the effect of DNA degradation on the detection in specimens is targeting of short DNA sequences $(<200$ base pair) in PCR. In our study, Real Time PCR for amplification has been used as a highly sensitive and specific method for evaluation (Baltzell et al., 2012).

We have detected EBV, MMTV and Merkel cell polyomaviruses positivity in 100 breast cancer tissues and the rate were (EBV 8\%), (MMTV 12\%) and (MPy 3\%) in Iranian patients and also it has been shown that from 100 lymph node tissues, EBV (22.2\%), MMTV (71.4\%) and Merkel cell polyomavirus $(17.7 \%)$ were positive by real time PCR.This data indicates that EBV, MMTV and Merkel cell polyomaviruses have an important role in breast cancer in Iran. Earlier reports confirm that expression of EBERs can promote the tumorogenic phenotype in infected cell and in our study the rate of EBER RNA was $18 \%$ in breast cancer samples and $55.5 \%$ in lymph nodes samples which confirmed the role of EBER RNA in cell transformation (Naderimagham et al., 2014; Veisy et al., 2015).

Our data proposed that EBV, MMTV and Merkel cell polyomavirus DNA presence in breast cancer patients can differ between groups with different ages and population characteristics and the size of tumors and ages can be varied in population. The prevalence of EBV, MMTV and Merkel cell polyomavirus nucleotide sequence in Iranian breast cancer patients could be detectable. In 2012, studied MMTV-like sequences in Iranian breast cancer in Shiraz, in southwest Iran and found no virus (Motamedifar et al., 2012). The p53 gene has cell cycle controlling role and p53 suppression by viral activity is leading to the development of neoplasm. Based on this fact we could show that the p53 rate in positive EBV, MMTV and Merkel cell polyomavirus cases were dropped comparing to negative samples (Vernet-Tomas et al., 2015). The oncogenic potential of MCPy Large T antigen with the cellular retinoblastoma tumor suppressor protein (pRb) has been proposed and in our study the increased expression rate of LTag in positive MCPy cases detected comparing to other positive and negative samples (Goetz et al., 2001). In a study, the env sequences inpre invasive lesions for the presence of MMTV was found in $19 \%$ of normal epithelial cells collateral to ductal carcinomas in situ (DCISs) or infiltrating ductal carcinomas (IDCs), $27 \%$ of atypical ductal hyperplasias, $82 \%$ of DCISs, and $35 \%$ of IDCs (Mazzanti et al., 2011). Inanother study, founded MMTV in 44 (72\%) of 61 paraffin-embedded IBC tumors, but did not compare with non-IBC tumors (Holland and Pogo, 2004).

Distribution of Immunochemistry markers such as CD34, p63, HER2, PR and ER were evaluated in Invasive Tumors, DCIS Tumors, DIN Tumors and Normal Tissues (Dabiri et al., 2013). In our study, CD34 and p63 have varied range compared to other markers. The mean rate of CD34 marker dropped in Invasive Tumors, DCIS Tumors, and DIN Tumors compared to normal cells, but on the other hand the increased level of p63 was shown in Invasive Tumors, DCIS Tumors, and DIN Tumors compared to normal cells. Further research is necessary to determine the role of EBV, MMTV and Merkel cell polyomavirus in the progression of breast cancer. These viruses were detected in the lymphocytes around the breast tissues, suggesting the contribution as a modulating agent in the microenvironment area around those breast tissues. Carcinogenesis can involve several factors and the role of 
viruses in most common cancers is certainly important. Viruses can act as direct transforming agents or cofactors. The most probable mechanism of carcinogenesis may involve a combination of genetic alterations, immune system dysfunctions, and viral infections. It is recommended that finding the exact relationship between EBV, MMTV and Merkel cell polyomavirus and breast cancer in Iranian patients needs further studies with an increased number of patients.

In conclusion, our findings suggest that EBV, MMTV and Merkel cell polyomavirus might have a role in the pathogenesis of breast cancer. These findings were based on EBV, MMTV and Merkel cell polyomavirus detection by real time PCR technique in breast cancer patients. So EBV, MMTV and Merkel cell polyomavirus may contribute to increased tumor aggression in patients from different ages and different geographic region.

\section{Acknowledgements}

The authors of this project are grateful to the Kerman Virology Laboratory in Besat clinic staff and their cooperation in collecting samples, and so thanks for Research Center of Infectious and Tropical Diseases ethics committee of the Kerman University of Medical Sciences in approving this project.

\section{References}

Ahangar Oskouee M, Shahmahmoodi S, Jalilvand S, et al (2014). No evidence of mammary tumor virus env genelike sequences among Iranian women with breast cancer. Intervirol, 57, 353-6.

Antonsson A, Bialasiewicz S, Rockett RJ, et al (2012). Exploring the prevalence of ten polyomaviruses and two herpes viruses in breast cancer. PLoS One, 7, 39842.

Arbach H, Viglasky V, Lefeu F, et al (2006). Epstein-Barr virus (EBV) genome and expression in breast cancer tissue: effect of EBV infection of breast cancer cells on resistance to paclitaxel (Taxol). J Virol, 80, 845-53.

Baltzell K, Buehring GC, Krishnamurthy S, et al (2012). EpsteinBarr virus is seldom found in mammary epithelium of breast cancer tissue using in situ molecular methods. Breast Cancer Res Treat, 132, 267-74.

Ban KA, Godellas CV (2014). Epidemiology of breast cancer. Surg Oncol Clin N Am, 23, 409-22.

Bindra A, Muradrasoli S, Kisekka R, et al (2007). Search for DNA of exogenous mouse mammary tumor virus-related virus in human breast cancer samples. J Gen Virol, 88, 1806-9.

Corbex M, Bouzbid S, Traverse-Glehen A, et al (2014). Prevalence of papillomaviruses, polyomaviruses, and herpesviruses in triple-negative and inflammatory breast tumors from algeria compared with other types of breast cancer tumors. PLoS One, $\mathbf{9}, 114559$.

Dabiri S, Talebi A, Shahryari J, et al (2013). Distribution of myofibroblast cells and microvessels around invasive ductal carcinoma of the breast and comparing with the adjacent range of their normal-to-DCIS zones. Arch Iran Med, 16, 93-9.

Darbre PD, Fernandez MF (2013). Environmental oestrogens and breast cancer: long-term low-dose effects of mixtures of various chemical combinations. J Epidemiol Community Health, 67, 203-5.
Deshpande CG, Badve S, Kidwai N, et al (2002). Lack of expression of the epstein-barr virus (EBV) gene products, EBERs, EBNA1, LMP1, and LMP2A, in breast cancer cells. Lab Invest, 82, 1193-9.

Fernandez MF, Santa-Marina L, Ibarluzea JM, et al (2007). Analysis of population characteristics related to the total effective xenoestrogen burden: a biomarker of xenoestrogen exposure in breast cancer. Eur J Cancer, 43, 1290-9.

Ford CE, Faedo M, Crouch R, et al (2004). Progression from normal breast pathology to breast cancer is associated with increasing prevalence of mouse mammary tumor virus-like sequences in men and women. Cancer Res, 64, 4755-9.

Forouzanfar MH, Foreman KJ, Delossantos AM, et al (2011). Breast and cervical cancer in 187 countries between 1980 and 2010: a systematic analysis. Lancet, 378, 1461-84.

Franci C, Zhou J, Jiang Z, et al (2013). Biomarkers of residual disease, disseminated tumor cells, and metastases in the MMTV-PyMT breast cancer model. PLoS One, 8, 58183.

Fukuoka H, Moriuchi M, Yano H, et al (2008). No association of mouse mammary tumor virus-related retrovirus with Japanese cases of breast cancer. J Med Virol, 80, 1447-51.

Goetz F, Tzeng YJ, Guhl E, et al (2001). The SV40 small $\mathrm{t}$-antigen prevents mammary gland differentiation and induces breast cancer formation in transgenic mice; truncated large T-antigen molecules harboring the intact p53 and $\mathrm{pRb}$ binding region do not have this effect. Oncogene, 20 , 2325-32.

Hippocrate A, Oussaief L, Joab I (2011). Possible role of EBV in breast cancer and other unusually EBV-associated cancers. Cancer Lett, 305, 144-9.

Holland JF, Pogo BG (2004). Mouse mammary tumor virus-like viral infection and human breast cancer. Clin Cancer Res, 10, 5647-9.

Ito H, Matsuo K (2015). Molecular epidemiology, and possible real-world applications in breast cancer. Breast Cancer.

Joshi D, Quadri M, Gangane N, et al (2009). Association of Epstein Barr virus infection (EBV) with breast cancer in rural Indian women. PLoS One, 4, 8180.

Mant C, Cason J (2004). A human murine mammary tumour virus-like agent is an unconvincing aetiological agent for human breast cancer. Rev Med Virol, 14, 169-77.

Mazouni C, Fina F, Romain S, et al (2011). Epstein-Barr virus as a marker of biological aggressiveness in breast cancer. Br J Cancer, 104, 332-7.

Mazouni C, Fina F, Romain S, et al (2015). Outcome of EpsteinBarr virus-associated primary breast cancer. Mol Clin Oncol, 3,295-8.

Mazzanti CM, Al Hamad M, Fanelli G, et al (2011). A mouse mammary tumor virus env-like exogenous sequence is strictly related to progression of human sporadic breast carcinoma. Am J Pathol, 179, 2083-90.

Melana SM, Picconi MA, Rossi C, et al (2002). [Detection of murine mammary tumor virus (MMTV) env genelike sequences in breast cancer from Argentine patients]. Medicina (B Aires), 62, 323-7.

Motamedifar M, Saki M, Ghaderi A (2012). Lack of association of mouse mammary tumor virus-like sequences in Iranian breast cancer patients. Med Princ Pract, 21, 244-8.

Naderimagham S, Alipour S, Djalalinia S, et al (2014). National and sub-national burden of breast cancer in Iran; 1990-2013. Arch Iran Med, 17, 794-9.

Paredes P, Vidal-Sicart S, Zanon G, et al (2005). Clinical relevance of sentinel lymph nodes in the internal mammary chain in breast cancer patients. Eur J Nucl Med Mol Imaging, 32, 1283-7.

Rahman M, Ahsan A, Begum F, et al (2015). Epidemiology, Risk Factors and Tumor Profiles of Breast Cancer in Bangladeshi 
underprivileged women. Gulf J Oncol, 1, 34-42.

Tabriz HM, Zendehdel K, Shahsiah R, et al (2013). Lack of detection of the mouse mammary tumor-like virus (MMTV) Env gene in Iranian women breast cancer using real time PCR. Asian Pac J Cancer Prev, 14, 2945-8.

Tao Z, Shi A, Lu C, et al (2014). Breast cancer: epidemiology and etiology. Cell Biochem Biophys.

Veisy A, Lotfinejad S, Salehi K, et al (2015). Risk of breast cancer in relation to reproductive factors in North-West of Iran, 2013-2014. Asian Pac J Cancer Prev, 16, 451-5.

Vernet-Tomas M, Banos N, Sabadell D, et al (2015). p53 expression in breast cancer predicts tumors with low probability of non-sentinel nodes infiltration. J Obstet Gynaecol Res.

Wang F, Hou J, Shen Q, et al (2014). Mouse mammary tumor virus-like virus infection and the risk of human breast cancer: a meta-analysis. Am J Transl Res, 6, 248-66.

Witt A, Hartmann B, Marton E, et al (2003). The mouse mammary tumor virus-like env gene sequence is not detectable in breast cancer tissue of Austrian patients. Oncol Rep, 10, 1025-9.

Yahia ZA, Adam AA, Elgizouli M, et al (2014). Epstein Barr virus: a prime candidate of breast cancer aetiology in Sudanese patients. Infect Agent Cancer, 9, 9. 